Berkala Ilmu Perpustakaan dan Informasi, Vol. 15, No. 1, Juni 2019, Hal. 10-20 DOI: $10.22146 /$ bip. 37868

ISSN 1693-7740 (Print), ISSN 2477-0361 (Online)

Tersedia online dihttps://jurnal.ugm.ac.id/bip

\title{
Produktivitas pengarang dan pertumbuhan artikel bidang arkeologi dalam Jurnal Kapata Arkeologi tahun 2005-2017
}

\author{
Bayu Indra Saputro ${ }^{1}$, Puspitaningrum Timur Utami ${ }^{2}$ \\ ${ }^{1}$ Balai Arkeologi Daerah Istimewa Yogyakarta \\ ${ }^{2}$ Peneliti Mandiri \\ e-mail: bayu.indra@kemdikbud.go.id
}

Naskah diterima: 06 Agustus 2018, direvisi: 12 November 2018, disetujui: 12 Februari 2019

\begin{abstract}
ABSTRAK
Pendahuluan. Produktivitas pengarang jurnal ilmiah di Indonesia masih tergolong rendah dibandingkan dengan negara-negara ASEAN. Penelitian ini bertujuan untuk mengetahui pola produktivitas pengarang dan juga pertumbuhan artikel bidang arkeologi pada jurnal Kapata Arkeologi yang diterbitkan oleh Balai Arkeologi Maluku dalam range waktu antara 2005 sampai 2017.

Metode penelitian. Metode dalam penelitian ini yaitu metode diskriptif dengan pendekatan kuantitatif, untuk mengetahui kontribusi pengarang dalam menghasilkan publikasi bidang arkeologi, mengetahui pola produktivitas pengarang dengan pengujian Hukum Lotka serta memberikan gambaran perkembangan publikasi bidang Arkeologi pada jurnal Kapata Arkeologi.

Data analisis. Analisis produktivitas pengarang menggunakan rumus dalil Hukum Lotka dan pengujian statistik dengan menggunakan teknik Kolmogorov Smirnov.

Hasil pembahasan. Pola produktivitas pengarang yang menghasilkan 1 artikel sebanyak 32,58\%, pengarang yang menghasilkan 2 artikel sebanyak 17,44\% yakni lebih dari seperempat pengarang yang menghasilkan 1 artikel, begitupun seterusnya. Pengarang yang paling banyak berkontribusi di jurnal Kapata Arkeologi adalah Wuri Handoko dengan 29 artikel. Artikel bidang Arkeologi Sejarah yang paling banyak diterbitkan dengan jumlah 76 artikel.

Kesimpulan dan Saran. Tingkat produktivitas pengarang jurnal Kapata Arkeologi sangat tinggi. Saran dari penelitian ini adalah perlu adanya keberlanjutan analisis bibliometrik terkait dengan kolaborasi pengarang.
\end{abstract}

Kata Kunci: Bibliometrika; Produktivitas; Pengarang; Lotka

\section{ABSTRACT}

Introduction. The productivity of scientific journals in Indonesia is still relatively low compared to other ASEAN countries. This study aims to determine author's productivity patterns as well as the growth trend of archaeological articles in the journal of Kapata Arkeologi published by Balai Arkeologi Maluku within the range from 2005 to 2017.

Data Collection Method. The method used in this research was descriptive quantitative, to examine the author's contribution in generating field of Archeology, understand the pattern of author's productivity by testing against the enactment of Lotka's Law and provide an overview of patterns of development publications by Kapata Archeologi.

Analysis Data. The author's productivity analysis used Lotka's Law and statistical testing by Kolmogorov Smirnov.

Results and Discussions. The productivity pattern showed that authors published one article was 32.58\%, 2 articles were $17.44 \%$ - meaning that more than a quarter of the author produced 1 article. The author who contributed most in Kapata Arkeologi was Wuri Handoko who has published 29 articles. Among other sub fields, Archaeological History articles are the most widely published article with a total of 76 articles. 
Conclusions. The productivity level of Kapata Archeology journal authors is very high. Further bibliometric analysis related to the collaboration of authors is needed.

Keywords: Bibliometrics; Productivity; Author; Lotka

\section{A. PENDAhULUAN}

Balai Arkeologi Maluku didirikan pada tahun 1995 dan berada di bawah Pusat Penelitian Arkeologi Nasional, Badan Penelitian dan Pengembangan Kebudayaan, Kementerian Pendidikan dan Kebudayaan. Instansi ini mempunyai tugas pokok dan fungsi yaitu melaksanakan penelitian arkeologi di wilayah kerja Maluku dan Maluku Utara, serta melaksanakan kegiatan penyebaran informasi hasil penelitian arkeologi kepada masyarakat luas. Kamus Besar Bahasa Indonesia (2016), menyatakan bahwa penelitian suatu kegiatan pengumpulan, pengolahan, analisis, dan penyajian data yang dilakukan secara objektif dan sistematis dalam menguji suatu hipotesis serta memecahkan masalah. Hasil penelitian arkeologi yang telah dilaksanakan oleh peneliti tersebut kemudian dituangkan dalam tulisan di dalam jurnal ilmiah.

Instansi Balai Arkeologi yang berada di Indonesia selalu menyediakan media untuk menampung penelitian ilmiah bagi para peneliti yang bernaung di bawahnya. Media tersebut digunakan sebagai alat untuk mengomunikasikan hasil penelitian yang telah dilaksanakan, baik itu peneliti dari lingkungan sendiri, peneliti luar instansi, pemerhati sejarah ataupun mahasiswa. Jurnal ilmiah merupakan kumpulan artikel ilmiah yang dipublikasikan secara periodik oleh suatu instansi penelitian ilmiah, sehingga penelitian dan publikasi karya ilmiah menjadi tulang punggung setiap negara dalam mempublikasikan karya ilmiah peneliti (Jacobs, 2001). Karena itulah, keberadaan jurnal ilmiah merupakan hal yang penting dalam memajukan ilmu pengetahuan dan teknologi. Untuk itu Balai Arkeologi Maluku menerbitkan jurnal Kapata Arkeologi agar peneliti dapat memberikan kajian-kajian pada bidang arkeologi dari seluruh Indonesia.

Jurnal Kapata Arkeologi diterbitkan pertama kali pada Volume 1 Nomor 1, Agustus 2005 hingga tahun berikutnya menjadi terbitan rutin dua kali dalam satu tahun. Jurnal Kapata
Arkeologi yang diterbitkan dapat dipercayai keabsahan penelitian dan kajian teori-teori tentang sejarah dan arkeologi. Hal ini dikarenakan jurnal Kapata Arkeologi sudah terakreditasi LIPI, sesuai dengan Surat Edaran Kepala LIPI No. nomor 678/Akred/P2MILIPI/07/2015. Kajian arkeologi yang disajikan pada jurnal Kapata Arkeologi seiring waktu semakin kompleks dengan perkembangan keilmuan yang ada. Menurut Lembaga Ilmu Penelitian Indonesia (2016, p. 122), terdapat 45 rumpun kepakaran peneliti. Dalam rumpun kepakaran peneliti tersebut dijabarkan lagi dalam beberapa bidang kepakaran dan bidang kepakaran dijabarkan lagi ke beberapa bidang penelitian. Fokus kajian dari jurnal Kapata Arkeologi yaitu ilmu arkeologi, sejarah, etnografi, dan disiplin ilmu lainnya yang berkaitan dengan manusia dan budaya. Bidangbidang inilah yang menjadi kajian bagi peneliti untuk menulis pada jurnal Kapata Arkeologi.

Bibliografi Arkeologi pada jurnal Kapata Arkeologi memberikan gambaran pertumbuhan bidang-bidang keilmuan dan gambaran pola produktivitas pengarang pada jurnal tersebut. Setiap perkembangan bidang arkeologi dan produktivitas pengarang pada jurnal Kapata Arkeologi harus dapat dipetakan dalam sebuah matrik statistik lewat suatu cabang ilmu bibliometrika.

Bibliometrika adalah suatu metode penelitian yang sudah diterapkan dalam bidang perpustakaan dan informasi yang menggunakan analisis kuantitatif dan statistik dalam menyelesaikan masalah penelitian yang sedang dilakukan (Sulistyo-Basuki, 2002, p. 3). Menurut Nuryudi (2016, p. 42), bibliometrika dikenal sebagai bidang kajian yang dapat mengungkapkan keunggulan suatu bidang ilmu tertentu lewat penerapan berbagai teori, seperti analisis kepengarangan, analisis sitiran, webometrik, kerjasama kepengarangan, keusangan dokumen, faktor dampak dan sebagainya. Disamping itu, dengan bibliometrika juga dapat diketahui bagaimana 
produktivitas dan sebaran atau distribusi publikasi ilmiah tersebut dalam bidang keilmuannya, serta ikut berperan dalam menyajikan peta perkembangan keilmuan Arkeologi.

Menurut Nuryudi (2016, p. 44) dalam menganalisis literatur secara kuantitatif dalam bibliometrika dikenal tiga hukum, yaitu Hukum Lotka untuk menghitung tingkat produktivitas pengarang pada jurnal ilmiah, Hukum Bradford yang menentukan jurnal inti subjek tertentu, dan Hukum Zipp untuk menghitung frekuensi pemunculan kata dalam sebuah dokumen.

Kepengarangan merupakan aspek yang penting dalam penyebaran informasi dan komunikasi ilmiah. Kontribusi pengarang dapat dilihat dari pola yang berbeda dengan adanya penulis tunggal dan kolaborasi (Aliyu, 2011, p. 33). Eksistensi pengarang pada suatu jurnal ilmiah menggambarkan produktivitas pengarang pada jurnal tersebut (SulistyoBasuki, 2006, p. 26). Sedangkan menurut (Mustafa, 2009, p. 9), mengatakan bahwa produktivitas pengarang merupakan jumlah hasil tulisan seorang pengarang yang dipublikasikan dalam kurun waktu tertentu. Produktivitas pengarang itu sendiri didefinisikan perbandingan antara hasil yang dicapai (jumlah artikel) dengan sumber daya yang digunakan (jumlah pengarang) (Rahayu, 2015, p. 3).

Pusat Penelitian Perkembangan Ilmu Pengetahuan Lembaga Ilmu Pengetahuan Indonesia meneliti dalam kurun waktu 20012010, lembaga penelitian dan pengembangan Korea Advanced Institute of Science and Technology (KAIST) menghasilkan publikasi internasional terbesar, yaitu 20.183 publikasi. Lembaga Japan Science and Technology Agency (JST) 13.604 dan Commonwealth Scientific and Industrial Research Organisation (CSIRO) Australia 11.611, sedangkan Lembaga Ilmu Pengetahuan Indonesia (LIPI) hanya memiliki 417 publikasi ilmiah. Jumlah publikasi ilmiah Indonesia bahkan lebih rendah dari negara-negara ASEAN, seperti Singapura, Thailand, dan Malaysia. Selama kurun waktu yang sama, jumlah publikasi ilmiah ketiga negara tersebut berkisar 30.000 publikasi, sedangkan Indonesia hanya menghasilkan total publikasi 7.843 atau 25 persennya. Hingga Desember 2012 jumlah jurnal ilmiah yang diserahkan ke PDII-LIPI untuk disebarluaskan tercatat lebih dari 7.000 jurnal ilmiah dan kurang dari 40.000 jurnal yang secara kontinyu mengirimkan terbitannya ke PDII-LIPI. Hingga Mei 2013 jurnal yang dapat diakses yaitu 5.700 judul baik dari Perguruan Tinggi maupun Lembaga Penelitian dengan lebih dari 96.000 artikel (Kompas, 2013).

Hal ini sesuai penelitian Saputro (2011, p. 85) bahwa dalam mengetahui pola produktivitas pengarang jurnal Berkala Arkeologi tahun 1980-2009 ditemukan bahwa produktivitas pengarang untuk setiap 1 hasil artikel adalah $44,81 \%$, pengarang yang menghasilkan 2 artikel sebanyak $18,00 \%$ dan pengarang yang menghasilkan 3 artikel sebanyak 10,56\%. Penelitian produktivitas pengarang pada jurnal Psikologi Universitas Gadjah Mada tahun 19852016 yang dilakukan oleh (Irianti, 2017, p.211), bahwa produktivitas pengarang untuk setiap 1 hasil artikel adalah $76,96 \%$, pengarang yang menghasilkan 2 artikel sebanyak $12,25 \%$ dan pengarang yang menghasilkan 3 artikel sebanyak $4,41 \%$. Disini terlihat adanya pola produktivitas pengarang yang berbeda walaupun penggunaan data pengarang jurnal dalam rentang waktu kurang lebih sama 29-31 tahun.

Penelitian ini bertujuan mengetahui pola produktivitas pengarang dari jurnal Kapata Arkeologi yang diterbitkan oleh Balai Arkeologi Maluku pada tahun 2005 hingga 2017 yang diukur secara kuantitatif menggunakan kajian ilmu bibliometrika, serta memberikan gambaran perkembangan keilmuan bidang arkeologi dengan melakukan komparasi semua sub-bidang subjek arkeologi.

Setelah tingkat produktivitas pengarang dalam menghasilkan karya ilmiah dihitung dengan rumus dalil Hukum Lotka maka peneliti akan melakukan pengujian statistik dengan menggunakan teknik Kolmogorov-Smirnov (goodness of fit). Pengujian ini dimaksudkan agar mendapatkan kesesuaian antara nilai distribusi frekuensi pengamatan dan nilai distributif frekuensi teoritis dalam penelitian ini, 
hal ini dilakukan untuk mendapatkan nilai estimasi yang tidak bias atau sesuai dengan nilai parameter.

Berdasarkan latar belakang masalah, maka fokus penelitian yaitu bagaimana hasil pengujian Hukum Lotka pada pola produktivitas dalam jurnal Kapata Arkeologi yang diterbitkan oleh Balai Arkeologi Maluku dalam kurun waktu 2005-2017, dan juga untuk mengetahui gambaran pertumbuhan artikel pada jurnal tersebut. Penelitian ini tidak hanya mengetahui produktivitas pengarang tetapi juga mengetahui perkembangan bidang studi yang ada pada jurnal yang diteliti.

\section{B. TINJAUAN PUSTAKA}

Penelitian tentang produktivitas pengarang dalam jurnal ilmiah yang diterbitkan oleh suatu instansi tertentu dimaksudkan untuk mengukur seberapa produktif para peneliti atau pengarang dalam lingkungan instansi tersebut menghasilkan karya ilmiah. Penelitian tentang produktivitas pengarang dalam menulis karya ilmiah lazimnya menggunakan dalil Hukum Lotka. Hukum Lotka adalah suatu bagian metode penelitian analisis bibliometrika.

Menurut Lotka (1926, p. 318), jika ada seratus orang yang menghasilkan 1 karya, akan ada seperempat dari seratus orang yang menghasilkan 2 karya, akan ada sepersembilan dari seratus orang yang akan menghasilkan 3 karya, dan akan ada seperenam belas dari seratus orang yang menghasilkan 4 karya, demikian seterusnya. Ini yang disebut hukum kuadrat terbalik dari Lotka mengenai produktivitas pengarang. Hukum kuadrat terbalik ini telah lama diterapkan oleh Alfred J Lotka untuk mengetahui hubungan antara jumlah pengarang dan jumlah artikel yang dihasilkannya. Artinya bahwa ada hubungan terbalik antara jumlah dokumen yang ditulis dengan jumlah pengarang yang menulis artikel. Dengan kata lain, semakin banyak artikel yang ditulis, semakin sedikit pengarang yang menulisnya.

Penelitian produktivitas pengarang jurnal dengan Hukum Lotka sudah mulai tumbuh di kalangan akademisi, baik yang dikaji oleh pustakawan maupun mahasiswa yang menyelesaikan studi akhir. Penelitian terdahulu terkadang hanya mengetahui pola produktivitas pengarang pada suatu jurnal ilmiah saja, seperti penelitian yang dilakukan oleh Nelisa, 2009; Saputro, 2011; dan Irianti, 2017. Dalam perkembangan kajian analisis bibliometrika selain untuk mengetahui pola produktivitas pengarang suatu jurnal juga dapat dikaji perkembangan suatu bidang ilmu jurnal tersebut. Seperti penelitian dilakukan oleh Nuryudi, 2016 yang mengkaji produktivitas pengarang serta perkembangan bidang ilmu Islam pada jurnal yang diterbitkan oleh UIN Syarif Hidayatullah Jakarta.

\section{METODE PENELITIAN}

Penelitian ini merupakan penelitian deskriptif dengan pendekatan kuantitatif, dimaksudkan untuk memperoleh data dan temuan secara deskriptif terhadap berbagai persoalan bibliometrika publikasi bidang arkeologi pada jurnal Kapata Arkeologi. Penelitian kuantitatif mengetahui kontribusi pengarang dalam menghasilkan publikasi bidang arkeologi melalui metode analisis bibliometrika dengan mengetahui pola produktivitas pengarang dengan dan pengujian terhadap berlakunya Hukum Lotka. Subjek penelitian ini adalah artikel jurnal Kapata Arkeologi dari tahun 2005-2017. Objek dari penelitian adalah pengarang artikel yang dimuat pada jurnal Kapata Arkeologi dalam kurun waktu tahun 2005-2017. Penelitian deskriptif akan memberikan gambaran yang detail tentang pola-pola kecenderungan perkembangan publikasi ilmiah bidang arkeologi pada jurnal Kapata Arkeologi.

Populasi adalah wilayah generalisasi yang terdiri atas subjek yang mempunyai kuantitas dan karakteristik tertentu yang ditetapkan oleh peneliti untuk diteliti dan ditarik kesimpulannya. Dalam penelitian ini populasinya adalah karya ilmiah yang dimuat dalam jurnal ilmiah bidang arkeologi yang diterbitkan oleh Balai Arkeologi Maluku dalam kurun waktu 2005-2017, sedangkan sampel dalam penelitian ini adalah artikel jurnal tersebut. 
Pemakaian data pengarang jurnal Kapata Arkeologi menggunakan nama pengarang yang pertama kali disebut dan pengarang lembaga (instansi) tidak digunakan dalam penelitian ini, sedangkan dalam menganalisis pertumbuhan ilmu arkeologi dalam jurnal tersebut penulis membatasi hanya pada rumpun kepakaran peneliti arkeologi, yaitu Bidang Arkeologi Prasejarah, Arkeologi Sejarah, Arkeologi Lingkungan dan Manajemen Arkeologi. Hal ini dikarenakan jurnal Kapata Arkeologi lebih berkonsentrasi terhadap bidang keilmuan arkeologi.

Teknik analisis data untuk mengetahui pola kepengarangan menerapkan langkah-langkah yang digunakan untuk pengujian Hukum Lotka terhadap data penelitian ini, yaitu:

1. Menentukan nilai-nilai pendugaan parameter Hukum Lotka menggunakan persamaan:

$$
C=\frac{1}{\sum \frac{1}{x^{n}}}
$$

2. Menghitung distribusi teoritis Hukum Lotka dengan persamaan:

$$
y_{x}=\frac{C}{x^{n}}
$$

3. Pengujian terhadap Hukum Lotka dengan menggunakan uji Kolmogorov-Smirnov (uji K-S)

Untuk keperluan uji K-S (Nelisa, 2009, p.81) menerapkan hipotesis nol (H_0) dan alternatifhipotesis ( $\mathrm{H}_{-}$1), dengan catatan: $\mathrm{H}_{0}=$ tidak ada perbedaan yang signifikan antara Hukum Lotka dan data yang ada.

$\mathrm{H}_{1}=$ ada perbedaan yang signifikan antara Hukum Lotka dan data yang ada.

Selain itu, juga ditentukan nilai kritis (tingkat kepercayaan 95\%) dengan persamaan: 1,36

$$
\overline{\sqrt{N}}
$$

Uji kesesuaian Hukum Lotka ditentukan dengan kriteria, apabila simpangan maksimum lebih kecil daripada nilai kritis, $\mathrm{H}_{0}$ diterima dan $\mathrm{H}_{1}$ data yang ditolak sehingga distribusi frekuensi yang diamati tidak memiliki perbedaan yang signifikan dengan Hukum Lotka. Sebaliknya, apabila simpangan maksimum lebih besar daripada nilai kritis, $\mathrm{H}_{0}$ ditolak dan $\mathrm{H}_{1}$ diterima sehingga distribusi frekuensi data yang diamati memiliki perbedaan yang signifikan dengan Hukum Lotka.

\section{HASIL DAN PEMBAHASAN Pola Produktivitas Pengarang Jurnal Kapata Arkeologi Tahun 2005-2017}

Data pengarang pada jurnal Kapata Arkeologi yang telah terbit sejak tahun 2005 hingga tahun 2017 diperoleh sebanyak 181 artikel dengan pengarang sebanyak 51 orang. Data yang telah dihimpun, kemudian diujikan dengan menggunakan persamaan kuadrat terbalik dari Hukum Lotka yaitu : $x^{n} \cdot y_{x}=C$ Dimana $\mathrm{x}$ merupakan banyaknya artikel yang ditulis oleh penulis, y merupakan banyaknya penulis yang menghasilkan $\mathrm{x}$ artikel, $\mathrm{C}$ adalah konstanta dan $n$ adalah banyaknya data $\mathrm{x}$. Dalam menghitung distribusi produktivitas dapat dilakukan setelah menentukan nilai-nilai dalam persamaan tersebut yaitu nilai $\mathrm{n}$ dan $\mathrm{C}$. Dalam menentukan nilai $\mathrm{n}$ digunakan persamaan sebagai berikut:

$$
n=\frac{N \sum X Y-\sum X \sum Y}{N \sum X^{2}-\left(\sum X\right)^{2}}
$$

Pada Tabel 1 diolah data pengamatan dan data kalkulasi distribusi pengarang dengan artikel yang dihasilkan selama tahun 2005 sampai dengan 2017.

Dengan data pada Tabel 1 maka diperoleh nilai ${ }^{a}$ adalah:

$$
\begin{aligned}
a & =\frac{12 \times 0,7027-10,2096 \times 3,0334}{12 \times 10,7707-(10,2096)^{2}} \\
& =-0,9010
\end{aligned}
$$

Karena $a=-n$, maka $n=0,9010$

Setelah nilai $n$ didapat, maka kemudian dicari nilai $C$. Dalam menentukan nilai $C$ digunakan rumus sebagai berikut:

$$
C=\frac{1}{\sum \frac{1}{x^{n}}}
$$

Dengan nilai $\mathrm{n}$ telah diketahui sebesar 0,9010 sehingga tabel distribusi frekuensinya seperti dapat dilihat pada Tabel 2 . 


$$
C=\frac{1}{3,0690}=0,3258
$$

Dari perhitungan ditemukan bahwa nilai $\mathrm{C}$ adalah 0,3258 yang berarti bahwa jumlah pengarang dengan 1 artikel merupakan suatu ketetapan pada pola tertentu yaitu 0,3258 . Maka persamaan menjadi:

$$
y_{x} \cdot x^{0,9010}=0,3258
$$

Dari persamaan diketahui bahwa distribusi frekuensi produktivitas pengarang hasil perhitungan pola produktivitas pengarang dengan menggunakan Hukum Lotka seperti pada Tabel 3 .

Dari hasil perhitungan dengan rumus hukum Lotka dapat dinyatakan bahwa pengarang yang menghasilkan 1 artikel sebanyak $32,58 \%$, pengarang yang menghasilkan 2 artikel sebanyak 17,44\% yakni lebih dari seperempat pengarang yang menghasilkan 3 artikel sebesar 12,18\%, yakni lebih dari sepersembilan jumlah pengarang yang menghasilkan 1 artikel, begitupun seterusnya. Secara umum dapat memperlihatkan bahwa terdapat hubungan antara jumlah pengarang dan jumlah artikel yang dihasilkan seperti pada hukum Lotka. Semakin kecil jumlah pengarang maka semakin banyak jumlah artikel yang ditulis.

Hasil yang didapat pada Tabel 3, menyatakan bahwa pengarang yang menghasilkan 1 artikel sebesar 32,58\%. Hal ini tidak sesuai dengan kesimpulan dari hukum Lotka yang menyatakan bahwa proporsi pengarang dengan satu artikel adalah $60 \%$ (Lotka A.J, 1926, p. 317). Namun Nicholls dalam Sobrino (2008, p. 26) menyatakan bahwa proporsi pengarang dari masing-masing data sampel jurnal yang diteliti tidaklah selalu tepat $60 \%$ sesuai dengan kesimpulan dalil hukum Lotka. Maka Nicholls memberikan perhatian akan Uji Kolmogorov-Smirnov untuk menguji kesesuaian Hukum Lotka ditentukan dengan kriteria, apabila simpangan maksimum lebih kecil daripada nilai kritis, $\mathrm{H}_{0}$ diterima dan $\mathrm{H}_{1}$ data yang ditolak sehingga distribusi frekuensi yang diamati tidak memiliki perbedaan yang signifikan dengan Hukum Lotka. Sebaliknya, apabila simpangan maksimum lebih besar daripada nilai kritis, $\mathrm{H}_{0}$ ditolak dan $\mathrm{H}_{1}$ diterima sehingga distribusi frekuensi data yang diamati memiliki perbedaan yang signifikan dengan Hukum Lotka. Untuk itu maka dilakukan Uji Kolmogorov-Smirnov seperti pada Tabel 4.

Nilai D maks adalah 0,2644, dimana $F_{0}\left(y_{x}\right)=\mathrm{y} / \sum y$ yaitu menghitung frekuensi penulis yang memberikan kontribusi $\mathrm{x}$ artikel dari data yang diamati, $\sum F_{0}\left(y_{x}\right)$ adalah menghitung frekuensi kumulatif penulis yang memberikan kontribusi $\mathrm{x}$ artikel, $F_{\theta}\left(y_{x}\right)=C / \boldsymbol{x}^{n}$ yaitu menghitung frekuensi penulis yang diharapkan memberikan kontribusi $\mathrm{x}$ artikel dari data yang diamati, $\sum F_{\varepsilon}\left(y_{x}\right)$ adalah menghitung frekuensi kumulatif penulis yang diharapkan memberikan kontribusi $\mathrm{x}$ artikel, dan $\mathrm{D}=\sum F_{0}\left(y_{x}\right)-\sum F_{\theta}\left(y_{x}\right)$ yaitu menghitung selisih antara frekuensi kumulatif penulis yang memberikan kontribusi $\mathrm{x}$ artikel dengan frekuensi kumulatif penulis yang diharapkan memberikan kontribusi $\mathrm{x}$ artikel. Kemudian diuji menggunakan nilai kritis $\frac{1,63}{\sqrt{N}}$ untuk $\propto=0,01$ atau taraf kepercayaan ternadap data sebesar $99 \%$ dan $N$ adalah total jumlah pengarang. Sehingga untuk mengetahui nilai kritisnya sebagai berikut:

$$
\frac{1,63}{\sqrt{N}}=\frac{1,63}{\sqrt{51}}=0,2282
$$

Distribusi hasil pengamatan menggunakan uji Kolmogorov-Smirnov dengan Dmaks $=0,2644$ pada nilai kritis 0,2282 menunjukkan bahwa nilai Dmaks lebih besar daripada nilai kritis sehingga diketahui bahwa hipotesis nol ditolak dan alternatif hipotesis diterima, yaitu terdapat perbedaan yang signifikan antara nilai teoritis Hukum Lotka dengan hasil pengamatan pada distribusi pengarang artikel Jurnal Kapata Arkeologi tahun 2005-2017.

Pengarang yang paling produktif dalam menerbitkan artikel pada jurnal Kapata Arkeologi dalam rentang tahun 2005-2017 adalah Wuri Handoko dengan artikel sebanyak 29 artikel. Wuri Handoko merupakan peneliti senior di lingkungan Balai Arkeologi Maluku dan mendalami kepakaran dalam bidang Arkeologi Sejarah Islam. Pengarang kedua yang paling produktif dalam menerbitkan karya ilmiah sebanyak 21 artikel adalah Marlon NR Ririmasse yang juga merupakan peneliti senior 
Balai Arkeologi Maluku yang mempunyai kepakaran dalam bidang arkeologi prasejarah, sedangkan pengarang produktif ketiga yakni Syahruddin Mansyur yang mempunyai kontribusi sebanyak 20 artikel. Beliau juga merupakan peneliti senior Balai Arkeologi Maluku dalam bidang Arkeologi Sejarah Kolonial, dan sekarang beliau bekerja di Balai Arkeologi Sulawesi Selatan.

Pengarang pria lebih banyak berkontribusi dalam tulisan dengan jumlah 33 orang dibandingkan dengan pengarang perempuan yang hanya berjumlah 18 orang. Hal ini dikarenakan faktor banyaknya peneliti pria di lingkungan Balai Arkeologi Maluku. Pengarang yang paling produktif berasal dari Balai Arkeologi Maluku sebanyak 7 orang, kemudian pengarang dari Balai Arkeologi Papua sebanyak 5 orang, Balai Arkeologi Jawa Barat, dan Universitas Hasanuddin masing-masing 4 orang dan seterusnya.

\section{Pertumbuhan Karya Ilmiah pada Bidang- Bidang Ilmu Arkeologi di Jurnal Kapata Arkeologi Tahun 2005-2017}

Jurnal dipandang telah berperan dalam peningkatan perkembangan kajian subjek yang telah ditentukan sumber analisis data. Jurnal tersebut terutama yang diterbitkan secara kontinuitas dengan bibliografi yang lengkap dan mudah diakses oleh pemustaka. Dari observasi diperoleh data artikel yang telah diterbitkan oleh Jurnal Kapata Arkeologi dalam kurun waktu 2005 sampai dengan 2017 berjumlah 181 artikel dari berbagai bidang arkeologi. Penelitian ini bertujuan memberikan gambaran pertumbuhan dan produktivitas karya ilmiah yang ada. Empat bidang kajian ilmu arkeologi yang telah diupayakan dianalisis, yakni Bidang Prasejarah, Arkeologi Sejarah, Arkeologi Lingkungan dan Manajemen Arkeologi sesuai dengan bidang kepakaran yang telah ditetapkan oleh LIPI.

Data pada Tabel 5 menunjukkan bahwa jumlah artikel yang diterbitkan pada Jurnal Kapata Arkeologi tahun 2005-2017 lebih banyak pada bidang Arkeologi Sejarah yang berjumlah 76 artikel. Hal ini mungkin dikarenakan pengarang yang berkontribusi pada jurnal ini lebih dominan peneliti dari Balai
Arkeologi Maluku dengan bidang kepakaran Arkeologi Sejarah. Bidang Arkeologi Sejarah tersebut meliputi bidang penelitian Arkeologi Hindu-Budha dan Arkeologi Islam-Kolonial.

Artikel kedua yang banyak diterbitkan di Bidang Manajemen Arkeologi sebanyak 65 artikel. Pada Bidang Manajemen Arkeologi meliputi kepakaran Arkeologi Publik, Pelestarian dan Manajemen Sumberdaya Arkeologi. Tulisan dalam bidang ini lebih banyak memuat tentang pelestarian cagar budaya peninggalan Islam-Kolonial dan arah kebijakan penelitian dari Balai Arkeologi Maluku, sedangkan artikel ketiga yang banyak diterbitkan pada jurnal Kapata Arkeologi pada bidang Arkeologi Prasejarah sebanyak 27 artikel, kemudian artikel pada bidang lain yang diterbitkan pada jurnal meliputi kajian Antropologi, Etnoarkeologi, Maritim dan lainlain sebanyak 11 artikel. Bidang Arkeologi Sejarah dan Manajemen Arkeologi sangat konsisten dalam menerbitkan karya-karyanya dalam rentang waktu 2005 hingga 2017. Walaupun pada tahun 2012 artikel kajian bidang Manajemen Arkeologi sempat tidak ada, tetapi jumlah terbitan tetap konsisten.

Data Tabel 6 menunjukkan bahwa artikel yang diterbitkan pada Jurnal Kapata Arkeologi tahun 2005-2017 tumbuh secara konsisten dengan rata-rata 14 artikel pertahun. Hal ini sesuai dengan fokus dari penerbitan artikel di jurnal Kapata Arkeologi adalah bidang Arkeologi.

\section{E. KESIMPULAN}

Produktivitas pengarang jurnal Kapata Arkeologi yang menghasilkan 1 artikel sebanyak $32,58 \%$, pengarang yang menghasilkan 2 artikel sebanyak 17,44\% yakni lebih dari seperempat pengarang yang menghasilkan 1 artikel, sehingga secara umum dapat memperlihatkan bahwa terdapat hubungan antara jumlah pengarang dan jumlah artikel yang dihasilkan seperti pada hukum Lotka. Distribusi hasil pengamatan menggunakan uji Kolmogorov-Smirnov dengan Dmaks $=0,2644$ pada nilai kritis 0,2282 menunjukkan bahwa nilai Dmaks lebih besar daripada nilai kritis sehingga diketahui bahwa 
hipotesis nol ditolak dan alternatif hipotesis diterima, yaitu terdapat perbedaan yang signifikan antara nilai teoritis Hukum Lotka dengan hasil pengamatan pada distribusi pengarang artikel Jurnal Kapata Arkeologi tahun 2005-2017.

Pengarang yang paling banyak berkontribusi dalam artikel ilmiah jurnal Kapata Arkeologi adalah Wuri Handoko dengan artikel yang telah terbit sebanyak 29 artikel. Pengarang pria lebih banyak berkontribusi dalam menerbitkan tulisan pada jurnal dengan jumlah 33 orang dibandingkan dengan pengarang perempuan yang hanya berjumlah 18 orang. Pada Jurnal Kapata Arkeologi tahun 2005-2017 lebih banyak menerbitkan artikel yang berkaitan bidang Arkeologi Sejarah yang berjumlah 76 artikel. Diharapkan kedepannya semakin banyak pengarang berkontribusi melalui karya ilmiah yang diterbitkan pada jurnal Kapata Arkeologi.

\section{DAFTAR PUSTAKA}

Aliyu, M. (2011). Author productivity and collaboration among academic scientists in Modibbo Adama University of Technology, Yola. The Information Manage, 11(1\&2), 32-35.

Badan Pengembangan dan Pembinaan Bahasa. (2016). Kamus Besar Bahasa Indonesia. Jakarta: Kementerian Pendidikan dan Kebudayaan. Diakses pada tanggal 12 November, 2018 , dari https:// kbbi.kemdikbud.go.id/entri/penelitian.

Irianti, P. (2017). Produktivitas penulis artikel majalah ilmiah Psikologi Universitas Gadjah Mada menggunakan Dalil Lotka. Berkala Informasi dan Perpustakaan, 13(2), 205-216. https://doi.org/10.22146/ bip. 26312

Jacobs, D. (2001). A bibliometric study of the publication patterns of scientists in South Africa 1992-1996, with special reference to gender difference. In Mari Davis (Ed.), 8th International Conference on Scientometrics and Informetrics Proceedings ISSI-2001 Volume 1, Sydney 16-20 July 2001. Australia: International Society for Scientometrics and Informetrics.
Kompas. Publikasi ilmiah dan paten Indonesia rendah. (n.d). Diakses pada tanggal 12 November, 2018 , dari http:// sains.kompas.com/read/2013/01/07/11454 710/Publikasi.Ilmiah.dan.Paten.IndonIndo .Rendah

Lembaga Ilmu Penelitian Indonesia. (2016). Pedoman pemilihan bidang kepakaran peneliti. Dikses pada tanggal 12 November 2018, dari http://jdih.lipi.go.id/view/ download.php?page $=$ peraturan\&id $=589$

Lotka, A. J. (1926). The frequency distribution scientific productivity. Journal of the Washington Academy of Sciences, 16(2), 317-323.

Mustafa. (2009). Hukum Lotka mengenai produktivitas pengarang. Diakses pada tanggal 5 Desember 2017 , dari http://docplayer.info/39233505-Hukumlotka-mengenai-produktifitas-pengarangoleh-b-mustafa-dan.html.

Nelisa, M. (2009). Produktivitas pengarang artikel bidang Ilmu Perpustakaan dan Informasi di Indonesia Tahun 1978-2007: Analisis Bibliometrika menggunakan Hukum Lotka. Jurnal Dokumentasi dan Informasi, 30(2), 73-95.

Nuryudi. (2016). Analisis bibliometrika Islam: studi kasus dokumentasi publikasi ilmiah di UIN Syarif Hidayatullah Jakarta. AlMaktabah: JurnaI Komunikasi dan Informasi Perpustakaan, 15(1), 41-55.

Rochani, N.R., \& Rulina, R. (2015). Kolaborasi dan produktivitas penulis artikel Visi Pustaka 2000-2014. Baca: Jurnal Dokumentasi dan Informasi, 36(2), 141-152.

Saputro, B. I. (2011). Analisis bibliometrika produktivitas pengarang artikel Jurnal Berkala Arkeologi dengan menggunakan dalil hukum Lotka. Berkala Arkeologi, 31(1), 73-88. 
Sobrino, M.I.M., Caldes, A.I.P., \& Guerrero, A.P. (2008). Lotka law to the scientific production of information science. Brazilian Journal of Information Science, 2(1), 16-30. https://doi.org/10.5016/ brajis.v2il.44 Diakses pada tanggal 5 Dese mber 2018 , dari http:// www2.marilia.unesp.br/revistas/index.php /bjis/article/view/44
Sulistyo-Basuki. (2002). Bibliometrika, sainsmetrika dan informetrika. In Makalah Kursus Bibliometrika (p. 3). Depok: Pusat Studi Jepang UI.

Sulistyo-Basuki. (2006). Perpustakaan dan informasi dalam konteks sosial budaya. Depok: Departemen Ilmu Perpustakaan \& Informasi, FIB UI. 


\section{DAFTAR TABEL}

Tabel 1. Data pengamatan dan data kalkulasi distribusi pengarang dengan artikel yang dihasilkan selama tahun 2005-2017

\begin{tabular}{cccccc}
\hline $\mathbf{x}$ & $\mathbf{y}$ & $\mathbf{X}=\log \mathbf{x}$ & $\mathbf{Y}=\log \mathbf{y}$ & $\mathbf{X Y}$ & $\mathbf{X}^{\mathbf{2}}$ \\
\hline 1 & 30 & 0 & 1,4771 & 0 & 0 \\
2 & 9 & 0,3010 & 0,9542 & 0,2872 & 0,0906 \\
3 & 2 & 0,4771 & 0,3010 & 0,1436 & 0,2276 \\
5 & 1 & 0,6989 & 0 & 0 & 0,4885 \\
6 & 1 & 0,7781 & 0 & 0 & 0,6055 \\
7 & 1 & 0,8450 & 0 & 0 & 0,7141 \\
8 & 2 & 0,9030 & 0,3010 & 0,2718 & 0,8155 \\
11 & 1 & 1,0413 & 0 & 0 & 1,0844 \\
12 & 1 & 1,0791 & 0 & 0 & 1,1646 \\
20 & 1 & 1,3010 & 0 & 0 & 1,6926 \\
21 & 1 & 1,3222 & 0 & 0 & 1,7482 \\
29 & 1 & 1,4623 & 0 & 0 & 2,1386 \\
Total & $\mathbf{5 1}$ & $\mathbf{1 0 , 2 0 9 6}$ & $\mathbf{3 , 0 3 3 4}$ & $\mathbf{0 , 7 0 2 7}$ & $\mathbf{1 0 , 7 7 0 7}$ \\
\hline
\end{tabular}

Sumber : Data primer diolah tahun 2018

Tabel 2. Tabel distribusi frekuensi dengan $n=0,9123$

\begin{tabular}{cccc}
\hline $\mathbf{x}$ & $\mathbf{y}$ & $\boldsymbol{x}^{\boldsymbol{n}}$ & $\mathbf{1} / \boldsymbol{x}^{\boldsymbol{n}}$ \\
\hline 1 & 30 & 1 & 1 \\
2 & 9 & 1,8673 & 0,5355 \\
3 & 2 & 2,6908 & 0,3716 \\
5 & 1 & 4,2635 & 0,2345 \\
6 & 1 & 5,0247 & 0,1990 \\
7 & 1 & 5,7734 & 0,1732 \\
8 & 2 & 6,5115 & 0,1535 \\
11 & 1 & 8,6755 & 0,1152 \\
12 & 1 & 9,3830 & 0,1065 \\
20 & 1 & 14,8671 & 0,0672 \\
21 & 1 & 15,5352 & 0,0643 \\
29 & 1 & 20,7788 & 0,0481 \\
Total & $\mathbf{5 1}$ & $\mathbf{9 6 , 3 7 1 2}$ & $\mathbf{3 , 0 6 9 0}$ \\
\hline
\end{tabular}

Sumber : Data primer diolah tahun 2018

Tabel 3.Pola produktivitas pengarang dengan menggunakan hukum Lotka

\begin{tabular}{cccc}
\hline $\mathbf{x}$ & $\mathbf{y}$ & $\boldsymbol{y}_{\boldsymbol{x}}$ & $\mathbf{\%}$ \\
\hline 1 & 30 & 0,3258 & 32,58 \\
2 & 9 & 0,1744 & 17,44 \\
3 & 2 & 0,1218 & 12,18 \\
5 & 1 & 0,0764 & 7,64 \\
6 & 1 & 0,0648 & 6,48 \\
7 & 1 & 0,0564 & 5,64 \\
8 & 2 & 0,0500 & 5,00 \\
11 & 1 & 0,0375 & 3,75 \\
12 & 1 & 0,0347 & 3,47 \\
20 & 1 & 0,0219 & 2,19 \\
21 & 1 & 0,0209 & 2,09 \\
29 & 1 & 0,0156 & 1,56 \\
Total & $\mathbf{5 1}$ & &
\end{tabular}


Tabel 4. Tabel uji Kolmogorov-Smirnov

\begin{tabular}{cccccccc}
\hline $\mathbf{x}$ & $\mathbf{y}$ & $\boldsymbol{x}^{\boldsymbol{n}}$ & $\boldsymbol{F}_{\mathbf{0}}\left(\boldsymbol{y}_{\boldsymbol{x}}\right)$ & $\sum \boldsymbol{F}_{\mathbf{0}}\left(\boldsymbol{y}_{\boldsymbol{x}}\right)$ & $\boldsymbol{F}_{\boldsymbol{e}}\left(\boldsymbol{y}_{\boldsymbol{x}}\right)$ & $\sum_{\boldsymbol{e}} \boldsymbol{F}_{\boldsymbol{e}}\left(\boldsymbol{y}_{\boldsymbol{x}}\right)$ & $\mathbf{D m a x}$ \\
\hline 1 & 30 & 1 & 0,5882 & 0,5882 & 0,3258 & 0,3258 & 0,2624 \\
2 & 9 & 1,8820 & 0,1764 & 0,7647 & 0,1744 & 0,5002 & $\mathbf{0 , 2 6 4 4}$ \\
3 & 2 & 2,7244 & 0,0392 & 0,8039 & 0,1210 & 0,6213 & 0,1825 \\
5 & 1 & 4,3418 & 0,0196 & 0,8235 & 0,0764 & 0,6977 & 0,1257 \\
6 & 1 & 5,1275 & 0,0196 & 0,8431 & 0,0648 & 0,7626 & 0,0805 \\
7 & 1 & 5,9017 & 0,0196 & 0,8627 & 0,0564 & 0,8190 & 0,0437 \\
8 & 2 & 6,6663 & 0,0392 & 0,9019 & 0,0500 & 0,8690 & 0,0328 \\
11 & 1 & 8,9137 & 0,0196 & 0,9215 & 0,0375 & 0,9066 & 0,0149 \\
12 & 1 & 9,6502 & 0,0196 & 0,9411 & 0,0347 & 0,9413 & 0,0002 \\
20 & 1 & 15,3790 & 0,0196 & 0,9607 & 0,0219 & 0,9632 & 0,0024 \\
21 & 1 & 16,0790 & 0,0196 & 0,9803 & 0,0209 & 0,9842 & 0,0038 \\
29 & 1 & 21,5846 & 0,0196 & 1 & 0,0156 & 0,9999 & 0,0001 \\
Total & $\mathbf{5 1}$ & & & & & & \\
\hline
\end{tabular}

Sumber : Data primer diolah tahun 2018

Tabel 5. Data artikel jurnal Kapata Arkeologi 2005-2017

\begin{tabular}{clc}
\hline No & \multicolumn{1}{c}{ Bidang Arkeologi } & Artikel \\
\hline 1 & Prasejarah & 27 \\
2 & Arkeologi Sejarah & 76 \\
3 & Arkeolog Lingkungan & 2 \\
4 & Manajemen Arkeologi & 65 \\
5 & Bidang Lainnya (Antropologi, & 11 \\
& Etnoarkeologi, Maritim, dll) & \\
\hline
\end{tabular}

Sumber : Data primer diolah tahun 2018

Tabel 6. Pertumbuhan artikel bidang arkeologi pada jurnal Kapata Akeologi 2005-2017

\begin{tabular}{|c|c|c|c|c|c|c|c|c|c|c|c|c|c|c|}
\hline \multirow{2}{*}{ No } & \multirow{2}{*}{ Bidang Arkeologi } & \multicolumn{13}{|c|}{ Tahun } \\
\hline & & 2005 & 2006 & 2007 & 2008 & 2009 & 2010 & 2011 & 2012 & 2013 & 2014 & 2015 & 2016 & 2017 \\
\hline 1 & Arkeologi Prasejarah & & 3 & 3 & & 2 & 1 & 4 & 2 & 1 & 4 & 1 & 4 & 1 \\
\hline 2 & Arkeologi Sejarah & 2 & 7 & 7 & 1 & 9 & 8 & 6 & 6 & 4 & 5 & 8 & 6 & 8 \\
\hline 3 & Arkeologi Lingkungan & & & & & & 2 & & & & & & & \\
\hline 4 & Manajemen Arkeologi & 4 & 3 & 11 & 17 & 3 & 4 & 2 & & 4 & 1 & 4 & 6 & 6 \\
\hline 5 & $\begin{array}{l}\text { Bidang Lain (Antropologi, } \\
\text { Etnoarkeologi, Maritim dll) }\end{array}$ & & & & 1 & & 1 & 1 & 2 & 1 & & & 2 & 3 \\
\hline & Jumlah & 6 & 13 & 21 & 19 & 14 & 16 & 13 & 10 & 10 & 10 & 13 & 18 & 18 \\
\hline
\end{tabular}

